\title{
Local Intra-arterial Vasodilator Infusion in Non-Occlusive Mesenteric Ischemia Significantly Increases Survival Rate
}

\author{
Robert Winzer $^{1}$ (D) Dieter Fedders ${ }^{1} \cdot$ Moritz Backes $^{1} \cdot$ Till Ittermann $^{2}$ • \\ Matthias Gründling ${ }^{3} \cdot$ Birger Mensel $^{4} \cdot$ Hanns-Christoph Held ${ }^{5} \cdot$ Marie-Luise Kromrey $^{6}$. \\ Jürgen Weitz ${ }^{5}$ Ralf-Thorsten Hoffmann ${ }^{1} \cdot$ Robin Bülow $^{6} \cdot$ Jens-Peter Kühn $^{1}$
}

Received: 14 October 2019/ Accepted: 2 May 2020

(C) The Author(s) 2020

\begin{abstract}
Purpose To investigate the outcome of local intra-arterial papaverine infusion therapy in patients with non-occlusive mesenteric ischemia (NOMI), and factors influencing survival, in comparison with a conservative approach.

Methods From 2013 to 2019, patients with NOMI confirmed by imaging were included in a retrospective twocenter study. According to different in-house standard procedures, patients were treated in each center either conservatively or interventionally by a standardized local infusion of intra-arterial papaverine into the splanchnic
\end{abstract}

The authors Robin Bülow and Jens-Peter Kühn have contributed equally.

Robert Winzer

robert.winzer@uniklinikum-dresden.de

$1 \quad$ Institute and Policlinic for Diagnostic and Interventional Radiology, University Hospital, Carl Gustav Carus

University, TU Dresden, Fetscherstr. 74, 01307 Dresden, Germany

2 Institute for Community Medicine, University Medicine Greifswald, Domstraße 11, 17489 Greifswald, Germany

3 Department of Anesthesia and Intensive Care, University Medicine Greifswald, Ferdinand-Sauerbruch-Straße, 17475 Greifswald, Germany

4 Zentrum für Diagnostische/Interventionelle Radiologie Und Neuroradiologie, Zentralklinik Bad Berka, Robert-KochAllee 9, 99438 Bad Berka, Germany

5 Visceral, Thoracic and Vascular Surgery, Carl Gustav Carus University, TU Dresden, Fetscherstr. 74, 01307 Dresden, Germany

6 Institute of Diagnostic Radiology and Neuroradiology, University Medicine Greifswald, Ferdinand-SauerbruchStraße, 17475 Greifswald, Germany arteries. Thirty-day mortality and factors influencing the outcome, such as different demographics and laboratories, were compared between groups using Kaplan-Meier survival analysis and Cox regression, respectively.

Results A total of 66 patients with NOMI were included, with $n=35$ treated interventionally (21 males, mean age $67.7 \pm 12.3$ years) and $n=31$ treated conservatively (18 females, mean age $71.6 \pm 9.6$ years). There was a significant difference in 30-day mortality between the interventional $(65.7 \% ; 12 / 35$ survived) and the conservative group (96.8\%; 1/31 survived) (hazard ratio 2.44; $P=0.005$ ). Thresholds associated with a worse outcome of interventional therapy are $>7.68 \mathrm{mmol} / 1$ for lactate, $<7.31$ for $\mathrm{pH}$ and $<-4.55$ for base excess.

Conclusion Local intra-arterial papaverine infusion therapy in patients with NOMI significantly increases survival rate in comparison with conservative treatment. High lactate levels, low $\mathrm{pH}$ and high base excess, and high demand for catecholamines are associated with a poor outcome. Level of Evidence Level III.

Keywords Mesenteric ischemia - Non-occlusive mesenteric ischemia - Papaverine - Infusion therapy · Patient outcome assessment

\section{Introduction}

Despite the progress in intensive care medicine, acute mesenteric ischemia is still a potentially lethal event due to insufficient blood supply of intestinal tissue over a critical 
time period [1]. Mesenteric ischemia can either result from arterial occlusion or be non-occlusive and result from severe lasting vasoconstriction (NOMI). For the latter form, a profound drop of systemic blood pressure is seen as causative for reflexive mesenteric arterial vasoconstriction and consecutive ischemia [2,3].

A mismatch of supply and demand in the intestine as a result of persistent mesenteric vasoconstriction leads to reduced blood flow as well as oxygen delivery particularly to the vulnerable superficial mucosa [4].

Therapy of shock in intensive care requires, among other things, the administration of catecholamines for circulatory stabilization. The aforementioned mismatch is amplified by the vasoconstrictive effect of catecholamines, starting a vicious circle. Left untreated, this can lead to gangrene of the intestinal wall, sepsis and multiple organ failure within a short time. Therefore, early diagnosis is crucial.

Generally, NOMI is diagnosed by computed tomography (CT) and confirmed by selective catheter angiography [5] with a further potential treatment option. Therefore, a catheter is placed in the affected vessel and a vasodilator is continuously infused over hours, resulting in vasodilation of splanchnic arteries.

At this time, interventional therapy is recommended by several boards [5]. These recommendations are based on few case reports with only a very limited number of patients [6-8]. Besides, these studies differ even concerning the type of vasodilator and the dosage used [9]; no comparative studies on different treatment protocols have been reported. Furthermore, there are no comparative studies about the outcome for patient groups which received interventional, versus noninterventional, treatment.

Therefore, the purpose of this study was to assess the outcome of local intra-arterial papaverine infusion therapy as an acute treatment in patients with NOMI, and factors influencing survival, in comparison with a conservative approach.

\section{Material and Methods}

The two-centered retrospective study was approved by both institutional review boards. The radiology information system of two university hospitals was searched for patients requiring intensive care treatment with an increasing demand for catecholamines, who had been diagnosed with NOMI by computed tomography from January 2013 to 2019, as shown in Table 1.

Due to different in-house standard operation procedures (SOP) for treatment for NOMI, patients received a "conservative therapy" at one center and additional local intra- arterial vasodilator infusion at the other center, described below as "interventional therapy."

\section{Intra-arterial Infusion of Vasodilators}

In general, mesenteric angiography was performed via the femoral artery using a $2.7 \mathrm{~F}, 4 \mathrm{~F}$ or $5 \mathrm{~F}$ introducer. Visceral arteries were intubated using a Cobra catheter $(\mathrm{C} 2$, Cordis, Baar, Switzerland) or SIM catheter (SIM1, Cordis, Baar, Switzerland).

NOMI was diagnosed if at least one of the following pathological findings was evident [9]:

(a) narrowing of the origins of branches of the superior mesenteric artery;

(b) irregularities in the intestinal branches;

(c) spasm of the arcades; and/or

(d) impaired filling of intramural vessels.

In cases of angiographic evidence of NOMI, the inserted diagnostic catheter was directly used for intra-arterial infusion of papaverine hydrochloride into the affected artery, i.e., the superior mesenteric artery or proper hepatic artery, respectively. If a stable position of the catheter was not possible, a microcatheter (Progreat 2.7 French, Terumo Cooperation, Tokyo, Japan) was placed in the affected vessel. After catheter placement, the vasodilator papaverine hydrochloride (Paveron N, $50 \mathrm{mg} / 2 \mathrm{ml}$, Linden Arzneimittel-Vertrieb-GmbH, Rastatt, Germany) was administered according to a predefined scheme: $50 \mathrm{mg}$ of Paveron $\mathrm{N}$ was dissolved in $50 \mathrm{ml}$ of isotonic saline applied for $1 \mathrm{~h}$. Subsequently, another $150 \mathrm{mg}$ of Paveron $\mathrm{N}$ in $50 \mathrm{ml}$ of isotonic saline was infused over $6 \mathrm{~h}$. If the patient's clinical symptoms did not improve, the second part of the scheme $(150 \mathrm{mg}$ of Paveron $\mathrm{N}$ in $50 \mathrm{ml}$ of isotonic saline) was repeated. The duration of papaverine infusion was based on the individual course and continued until clinical improvement or death. Clinical improvement was determined by the primarily treating intensive care specialist. Criteria of clinical improvement were hemodynamic recovery (norepinephrine dose reduction), a decrease in organ dysfunction (SOFA score) and resolution of paralytic ileus (bowel movement). In general, no additional anticoagulation was provided unless required by preexisting diseases.

\section{Diagnostics and Therapy Approach at the Conservative Center}

At the conservative center, diagnosis of NOMI was based on clinical findings and by interpreting morphologic appearance and diameter of SMA [10], in conjunction with previous CT scans, where available, [11] as shown in Fig. 1. 
Table 1 Inclusion and exclusion criteria

\begin{tabular}{|c|c|}
\hline Inclusion criteria & Exclusion criteria \\
\hline Intensive care treatment with an increasing demand for catecholamines & $\begin{array}{l}\text { SMA occlusion at angiographic } \\
\text { CT phase }\end{array}$ \\
\hline Clinical/laboratory indications for bowel ischemia & $\begin{array}{l}\text { SMV occlusion at portal venous } \\
\text { CT phase }\end{array}$ \\
\hline $\begin{array}{l}\text { Signs of hypoperfusion and elevation of serum lactic acid without evidence of any other diagnosis that } \\
\text { could explain these findings }\end{array}$ & Bowel obstruction at CT \\
\hline \multicolumn{2}{|l|}{ Biphasic abdominal CT } \\
\hline \multicolumn{2}{|l|}{ Age $>18$ years } \\
\hline
\end{tabular}

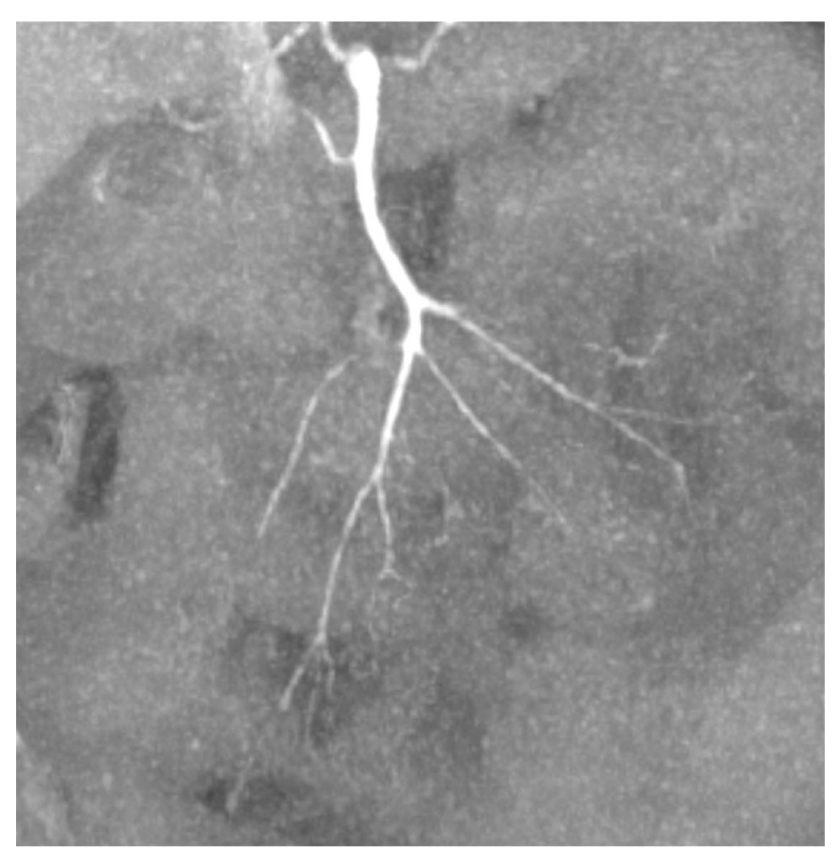

Fig. 1 Coronary maximum intensity projection (MIP) of a patient with mesenteric ischemia confirmed by surgery: irregular stenosis of SMA branches and poor visualization of intestinal arcade. SMAsuperior mesenteric artery

The conservative therapeutic approach is primarily based on rapid diagnosis and fluid therapy before a systemic inflammatory response can develop. Fluid therapy aims to restore adequate organ and tissue perfusion $[12,13]$.

\section{Clinical Parameters}

Demographics, such as age and gender, laboratory parameters (e.g., lactate serum level, pH, base excess), SOFA score and comorbidities were documented on the day of diagnosis in order to determine a possible influence on survival. If the laboratory parameters showed a significant influence on survival, these parameters are described in the Results section.

Catecholamine noradrenaline dose was evaluated directly before treatment and within $24 \mathrm{~h}$ after treatment or in the follow-up of conservative therapy, respectively.

Finally, we recorded the following comorbidities: tumor, cardiovascular, metabolic, pulmonary, renal and other diseases.

\section{Statistical Analysis}

Statistical analysis was performed using Stata 15.1 (Stata Corporation, College Station, TX, USA).

Characteristics of the study population are given by means and standard deviations for continuous variables and as absolute numbers for categorical variables stratified by group.

Thirty-day mortality was the primary endpoint of this study. Differences in mortality between interventional and conservative groups were analyzed by Kaplan-Meier survival analysis, log-rank testing and Cox regression. If there was significant group difference, Kaplan-Meier analysis was adjusted for the differing covariate [14]. In the interventional group, we analyzed associations of laboratory biomarker concentrations before intervention, including lactate, $\mathrm{pH}$ and base excess with 30-day mortality by Cox regression. For these biomarkers, we calculated optimal cutoffs discriminating best for 30-day mortality by maximizing the Youden index (sensitivity + specificity-1). In all analyses, a $p<0.05$ was considered as statistically significant. 


\section{Results}

Thirty-five patients (21 male, average age of $67.7 \pm 12.3$ years) of the interventional therapy group matched the inclusion criteria with diagnostic findings compatible with NOMI.

Interventions were performed by five interventional radiologists with 1-12 years of experience. The average duration (table time) of the diagnostic angiography and the time for catheter placement for papaverine hydrochloride treatment were $43 \pm 27$ min (range: 15-135 min). Only one patient had a peri-interventional dissection of the external iliac artery caused by chronic stenosis, which was successfully treated with a stent.

In the majority of patients, the catheter was placed in the mesenteric artery (32/35 patients). In three cases, the catheter was positioned into the hepatic artery, because vasoconstriction was most pronounced there. Interventional radiologists used the following catheter for intraarterial infusion: $2.7 \mathrm{~F}$ microcatheter $(n=16 / 35 ; 45.7 \%)$; $4 \mathrm{~F}$ diagnostic catheter $(n=14 / 35 ; 40.0 \%)$; and $5 \mathrm{~F}$ diagnostic catheter $(n=5 / 35 ; 14.3 \%)$. Patients had a mean papaverine hydrochloride infusion time of $26 \pm 26 \mathrm{~h}$ (range: 1-101 h). An example of successful interventional treatment is shown in Fig. 2.

In the conservative study center, 31 patients (18 male, average age of $71.6 \pm 9.6$ years) matched the inclusion criteria with diagnostic findings compatible with NOMI.

A comparison of both groups revealed only a significant difference for lactate (interventional group: $8.8 \pm 6.8 \mathrm{mmol} / \mathrm{l}$, conservative group: $12.7 \pm 7.9 \mathrm{mmol} / \mathrm{l}$; $P=0.025)$. After adjusting the survival analysis for the covariate lactate, there was still a significant survival benefit for patients treated with intra-arterial papaverine $(p<0.05)$. Figure 3 presents the Kaplan-Meier plot for 30-day mortality.

For the interventional treatment group, post-interventional 30 -day mortality was $65.7 \%$ (12 surviving patients), while patients with conservative therapy had a $96.8 \%$ mortality (only one surviving patient), revealing a significant difference (hazard ratio $2.44 ; P=0.005$, adjusted for the covariate lactate).

For all other demographics, laboratory data, the SOFA score, catecholamine doses and comorbidities, no significant differences were found, as shown in Table 2.

Causes of NOMI were identified and are presented in Table 3. The only significant differences were in the frequency of sepsis $(p=0.008)$ and pancreatitis $(p=0.016)$. More importantly, none of the diseases mentioned had a significant impact on survival.

Lactate serum levels, $\mathrm{pH}$, base excess and high demand of noradrenaline before intervention were significantly associated with 30-day mortality adjusted for age and sex in the interventional group (Table 4).

Thresholds to discriminate between those who died and those who survived after 30 days were $>7.68 \mathrm{mmol} / \mathrm{l}$ for lactate, $<7.32$ for $\mathrm{pH},<-4.55$ for base excess and $>$ $0.0009 \mathrm{mg} / \mathrm{kg} / \mathrm{body}$ weight for noradrenaline.

\section{Discussion}

In our study, we assessed the impact of acute treatment of NOMI by local infusion of papaverine hydrochloride into splanchnic arteries in comparison with conservative noninterventional treatment. Our data indicate that intra-arterial therapy with papaverine hydrochloride increases the survival rate. Besides, an increased lactate serum level, a reduced $\mathrm{pH}$, a negative base excess and a high demand for
Fig. 2 Angiography of the superior mesenteric artery in a patient with NOMI: Irregularities in the intestinal branches and spasm of the arcades confirmed the diagnosis of NOMI (A). There were no more abnormalities of vascular branches visible $6 \mathrm{~h}$ after local infusion of papaverine (B)

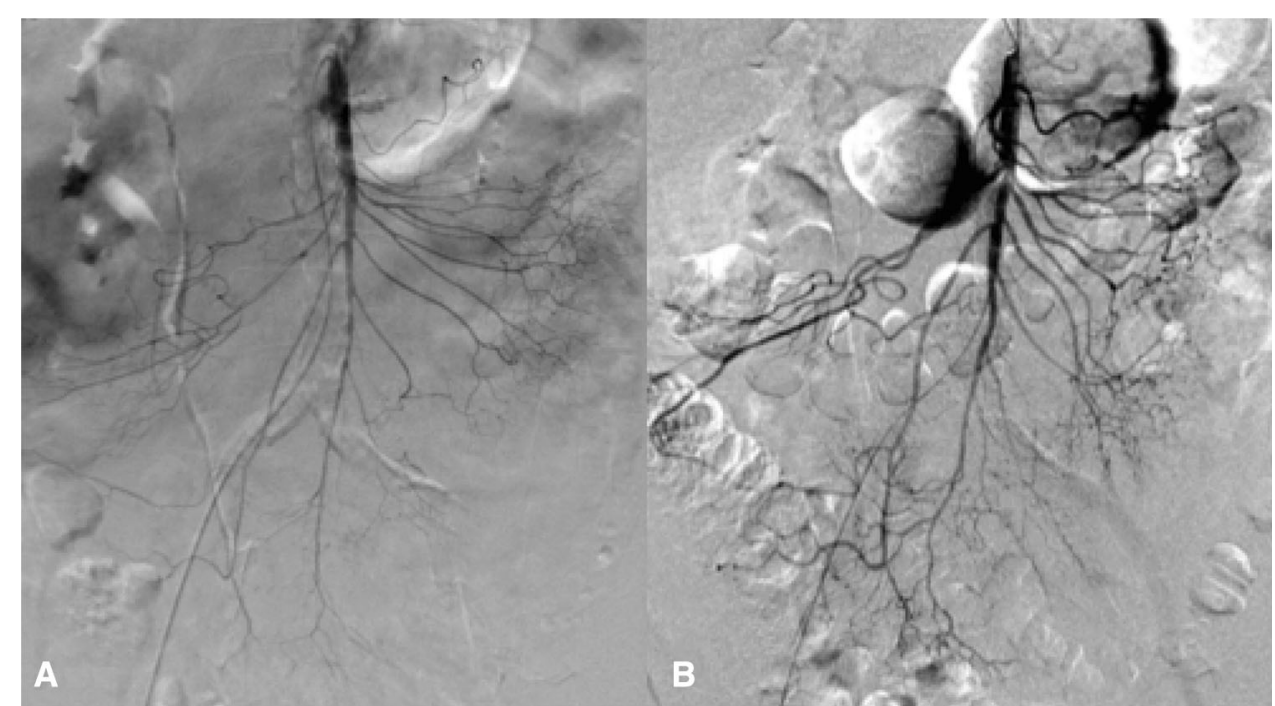


Fig. 3 Kaplan-Meier plot for 30-day mortality shows significant differences between patients with NOMI treated interventionally and conservatively $(p=0.005)$

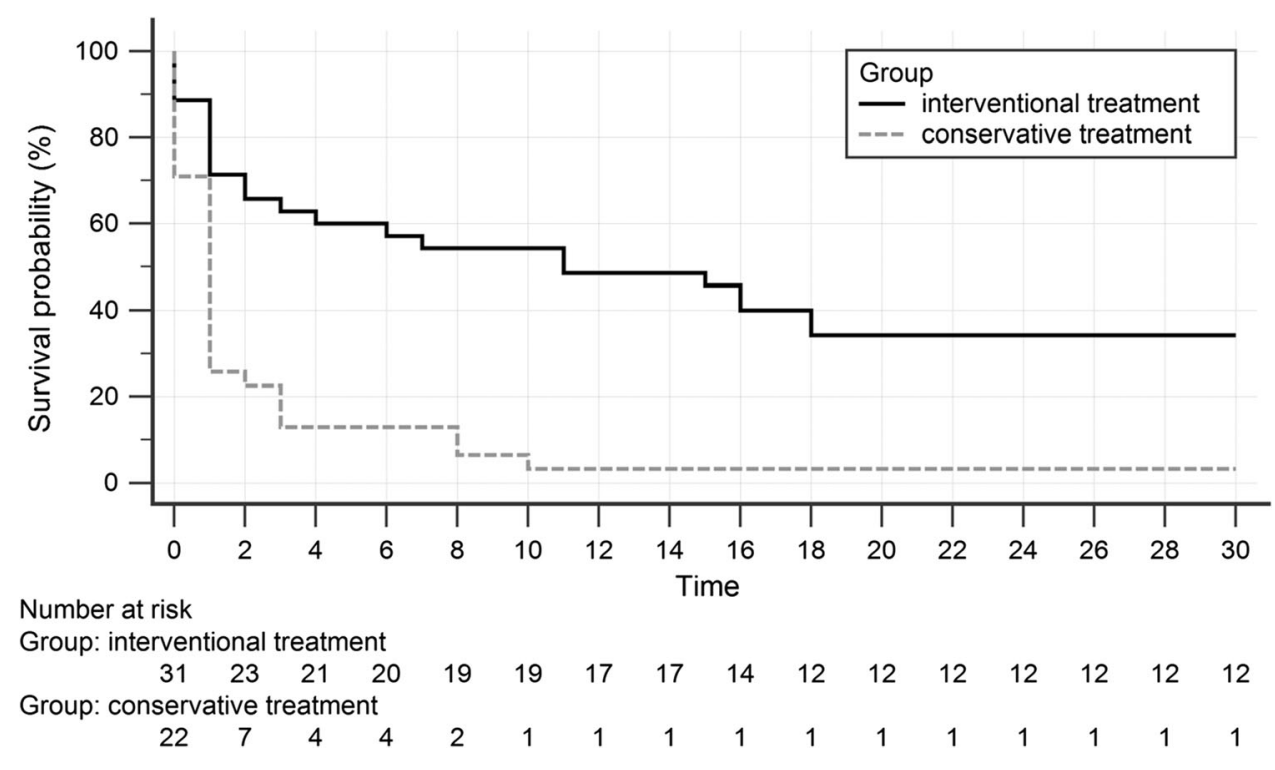

Table 2 Demographics and clinical parameters of patients with NOMI in interventional and conservative treatment

\begin{tabular}{|c|c|c|c|}
\hline & \multicolumn{3}{|l|}{ Therapy } \\
\hline & Interventional (mean \pm standard deviation) & Conservative (mean \pm standard deviation) & $p$ \\
\hline$n$ & 35 & 31 & \\
\hline Age in years & $67.7 \pm 12.3$ & $71.6 \pm 9.5$ & 0.225 \\
\hline Gender (f/m) & $14 / 21$ & $18 / 13$ & 0.143 \\
\hline SOFA score & $10.94 \pm 2.5$ (two missing) & $10.93 \pm 2.9$ (one missing) & 0.993 \\
\hline Lactate in $\mathrm{mmol} / \mathrm{l}$ & $8.8 \pm 6.8$ & $12.7 \pm 7.9$ & 0.025 \\
\hline Noradrenaline dose in $\mathrm{mg} / \mathrm{kg} /$ body weight & $0.0019 \pm 0.0025$ & $0.0012 \pm 0.0014$ & 0.667 \\
\hline Base excess & $-4.76 \pm 7.72(1 \mathrm{missing})$ & $-6.47 \pm 8.39(1 \mathrm{missing})$ & 0.399 \\
\hline $\mathrm{pH}$ & $7.29 \pm 0.13(1 \mathrm{missing})$ & $7.25 \pm 0.16(1$ missing $)$ & 0.212 \\
\hline \multicolumn{4}{|l|}{ Comorbidities\# } \\
\hline Cardiovascular & $26 / 35$ & $23 / 31$ & 0.993 \\
\hline Cancer & $7 / 35$ & $11 / 31$ & 0.159 \\
\hline Metabolic & $8 / 35$ & $8 / 31$ & 0.780 \\
\hline Pulmonary disease & $4 / 35$ & $4 / 31$ & 0.855 \\
\hline Renal disease & $9 / 35$ & $13 / 31$ & 0.163 \\
\hline Others & $10 / 35$ & $9 / 31$ & 0.967 \\
\hline
\end{tabular}

noradrenaline prior to intervention are associated with a poor patient outcome.

NOMI leads to bowel ischemia by a constriction of mesenteric vessels [15]. Therefore, intra-arterial administration of vasodilators may reduce vasospasm and thereby prevent mesenteric necrosis. For the treatment regimen and the applied vasodilators, studies published so far are based on small patient cohorts only [6, 16-25]. When considering papaverine for intra-arterial therapy, only four studies have been published until now with ten to 25 patients $[6,17,19,23]$. No direct comparison with a conservative noninterventional treatment has been done so far. A study from 1977 showed that persistent mesenteric vasoconstriction could be disrupted by the selective administration of papaverine hydrochloride $(60 \mathrm{mg} / \mathrm{h}$ continuous infusion dose) into the mesenteric artery [6] and nine of 15 patients survived (survival rate 60\%). Clark et al. [17] achieved similar results (survival rate $45 \%$, five out of 11 patients) with either papaverine hydrochloride $(30-60 \mathrm{mg} / \mathrm{h}$ continuous infusion dose) or prostaglandin E2 (one patient, 0.6 to $1.5 \mathrm{mg} / \mathrm{h}$ infusion rate). Klotz et al. demonstrated a survival rate of $64 \%$ (nine out of 14 cases) in their 
Table 3 Causes of NOMI by treatment group

\begin{tabular}{lllll}
\hline & \multicolumn{2}{l}{ Therapy } & & \\
\cline { 3 - 5 } \cline { 3 - 4 } & Interventional (number of patients) & Conservative (number of patients) & $p$ \\
\hline Cardiac emergencies & 11 & 8 & 0.262 \\
Postoperative condition & 4 & 2 & 0.314 \\
Sepsis & 11 & 3 & 0.008 \\
Hemorrhagic shock & 4 & 3 & 0.856 \\
Shock by other causes & 1 & 3 & 0.367 \\
Pancreatitis & - & 6 & 0.016 \\
Lung failure & - & 4 & 0.098 \\
Other diseases & - & 6 & - \\
\hline
\end{tabular}

Table 4 Association of biomarkers prior to intervention with 30-day mortality in the group with interventional treatment $(n=35)$

\begin{tabular}{|c|c|c|c|c|c|c|}
\hline Biomarker & $\begin{array}{l}\text { Hazard ratio by } 1 \mathrm{SD} \text { of the biomarker }(95 \%- \\
\mathrm{CI})^{*}\end{array}$ & $p^{*}$ & $\begin{array}{l}\text { Threshold } \\
\text { value }\end{array}$ & $\begin{array}{l}\text { Youden } \\
\text { index }\end{array}$ & $\begin{array}{l}\text { Sens } \\
\%\end{array}$ & $\begin{array}{l}\text { Spec } \\
\%\end{array}$ \\
\hline Lactate; $\mathrm{mmol} / \mathrm{l}$ & $1.96(1.26 ; 3.07)$ & 0.003 & $>7.68$ & 0.49 & 65 & 83 \\
\hline $\mathrm{pH}$ & $0.46(0.28 ; 0.74)$ & 0.001 & $<7.32$ & 0.49 & 65 & 83 \\
\hline Base excess & $0.50(0.28 ; 0.87)$ & 0.015 & $<-4.55$ & 0.52 & 77 & 55 \\
\hline $\begin{array}{l}\text { Noradrenaline; } \mathrm{mg} / \mathrm{kg} / \mathrm{body} \\
\text { weight }\end{array}$ & $1.41(1.02 ; 1.96)$ & 0.040 & $>0.0009$ & 0.40 & 65 & 75 \\
\hline
\end{tabular}

*Derived from Cox regression adjusted for age and sex

$S D$ standard deviation; $C I$ confidence interval; Sens sensitivity; and Spec specificity

interventionally treated cases using $53.5 \pm 12.5 \mathrm{mg} / \mathrm{h}$ papaverine hydrochloride continuous infusion dose (bolus of $60 \mathrm{mg}$ of papaverine in two cases) [19].

In comparison with previous studies, we gained a lower survival rate of $34.3 \%$ for patients treated with infusion therapy of papaverine hydrochloride in the setting of NOMI. The lower survival rate in our study may be explained by the fact that our study groups had higher lactate levels in comparison with previous research $[19,21,25,26]$; lactate values on studies with local infusion of papaverine hydrochloride are only mentioned by Klotz et al. [19] (mean lactate for severe NOMI: $0.4 \pm 0.5 \mathrm{mmol} / \mathrm{l})$. While there was no linear relationship between lactate levels and the extent of ischemia in a study by Ambe et al. [27], higher levels of lactate were found in those with advanced ischemia. To compare survival with previous studies, we performed a threshold analysis on lactate regarding 30-day mortality. With an AUC of 0.79, lactate is suitable as a biomarker for differentiating between surviving and deceased patients [28]. Above the calculated cutoff lactate level of $7.68 \mathrm{mmol} / 1,88 \%$ of these patients (15 of 17 patients) died. For interventionally treated patients with lactate levels below the threshold, survival rates were comparable to the studies on papaverine hydrochloride (averaged survival 52\%) with a survival rate of 55\% (ten of 18 patients), although our therapy regimen was different.

There has not been any recommendation or standardization so far regarding the dosage of papaverine hydrochloride for interventional treatment. Current research recommends a wide range of papaverine hydrochloride doses between 10 and $60 \mathrm{mg} / \mathrm{h}$ $[6,17,19,26,29]$. Thus, further research should suggest an optimal dosage for papaverine hydrochloride treatment of NOMI.

Furthermore, there are promising results using other vasodilators [18, 21, 24, 30], such as tolazoline, vasopressin, prostacyclins or prostaglandins. There has not been any recommendation thus far regarding the type of drugs applied for local arterial treatment. For example, in a recent experimental study by Mahlke et al. [30], iloprost, PGE1 and papaverine dilated pre-constricted human mesenteric arteries by a similar degree in vitro. Iloprost sensitivity was higher in vessels with a small lumen diameter, which is particularly suitable for the treatment for NOMI. Based on our experience, iloprost shows pronounced systemic side effects, like hypotension and tachycardia in clinical practice. Therefore, we prefer papaverine for intra-arterial therapy of NOMI.

In our study, we revealed increased lactate serum levels, a reduced $\mathrm{pH}$, a negative base excess and a high demand 
for noradrenaline prior to intervention as factors leading to a poor patient outcome. In critical patient conditions, these laboratory parameters are generally associated with a worse outcome. Therefore, close observation of laboratory parameters, early screening for NOMI and well-timed intra-arterial therapy may increase the likelihood of survival.

Considering previous studies [6, 17-25] and our results, interventional treatment seems to have a distinctive advantage for patients' outcome regardless of the scheme and vasodilator applied. To the best of our knowledge, this study is the first to directly compare an interventional treatment with papaverine hydrochloride and conservative treatment approach of NOMI. Besides, in our study cohort, size of patients was by far the largest to date.

The study has several limitations. First, the study design was retrospective. Although the results are promising in terms of mortality reduction, there are no prospective, randomized studies that can prove the benefits of intraarterial vasodilator therapy.

Another limitation lies in the comparability of both groups. As serum lactate levels at the time of the diagnosis differed substantially $\quad(8.8 \pm 6.8 \mathrm{mmol} / \mathrm{l} \quad$ vs. $12.7 \pm 7.9 \mathrm{mmol} / 1, \quad p=0.025)$, survival analysis was adjusted for covariate lactate. There was still a distinct survival benefit of interventional therapy in patients with NOMI $(p=0.005)$. Further, we used the SOFA score, which is a consensus established by the European Society for Intensive Care Medicine (ESICM) for the objective description of organ dysfunction, to compare subgroups regarding expected mortality. Both groups had similar SOFA scores $(10.94 \pm 2.5$ vs. $10.93 \pm 2.9, p=0.993)$ at the time of diagnosis. Furthermore, there were no other significant differences according to demographic and laboratory data. Finally, we cannot exclude that there are further relevant differences (e.g., differences in medical care and protocols for early detection of sepsis and SIRS) between both groups that could have influenced our results.

In conclusion, our data suggest a significant benefit of local intra-arterial papaverine infusion therapy regarding 30-day mortality in the treatment for NOMI in comparison with a conservative therapy approach. To improve the probability of survival, in the first step, diagnostics of NOMI should be much more sensitive to detect patients at an earlier stage of ischemia. In the second step, standard operation procedures at both centers should include interventional therapy, which requires appropriate training as well.

High lactate levels, low $\mathrm{pH}$ and high base excess and high demand for catecholamines are associated with a poor patient outcome of interventional treatment. If NOMI is suspected either by imaging or clinical signs, we would recommend an immediate selective angiography to confirm diagnosis, followed by an intra-arterial papaverine infusion as treatment for NOMI.

Acknowledgements A sincere thank you to Christian Pirke and Matthias Diestel for their diligent proofreading of this manuscript.

Funding This study was not supported by any funding.

\section{Compliance with ethical standards}

Conflict of interest To the best of our knowledge, this study is the first to compare an interventional and conservative treatment approach of NOMI directly. We confirm that this manuscript or similar work has not been published elsewhere and is not under consideration by another journal. There was no conflict of interest: Robert Winzer, MD: nothing to disclose, Dieter Fedders, MD: nothing to disclose, Moritz Backes: nothing to disclose, Till Ittermann: nothing to disclose, Matthias Gründling, MD: nothing to disclose, Birger Mensel, MD: nothing to disclose, Hanns-Christoph Held, MD: nothing to disclose, Marie-Luise Kromrey, MD: nothing to disclose, Jürgen Weitz, MD: nothing to disclose, Ralf-Thorsten Hoffmann, MD: nothing to disclose, Jens-Peter Kühn, MD: nothing to disclose, Robin Bülow, MD: nothing to disclose.

Ethical approval For this type of study, formal consent is not required. The ethics committees of the University Medical Center Dresden and Greifswald confirmed the study.

Informed consent This study has obtained IRB approval from the relevant board, and the need for informed consent was waived.

Consent for publication For this type of study consent for publication is not required.

Open Access This article is licensed under a Creative Commons Attribution 4.0 International License, which permits use, sharing, adaptation, distribution and reproduction in any medium or format, as long as you give appropriate credit to the original author(s) and the source, provide a link to the Creative Commons licence, and indicate if changes were made. The images or other third party material in this article are included in the article's Creative Commons licence, unless indicated otherwise in a credit line to the material. If material is not included in the article's Creative Commons licence and your intended use is not permitted by statutory regulation or exceeds the permitted use, you will need to obtain permission directly from the copyright holder. To view a copy of this licence, visit http://creativecommons. org/licenses/by/4.0/.

\section{References}

1. Acosta S. Epidemiology of mesenteric vascular disease: clinical implications. Semin Vasc Surg. 2010;23(1):4-8.

2. Reinus JF, Brandt LJ, Boley SJ. Ischemic diseases of the bowel. Gastroenterol Clin N Am. 1990;19(2):319-43.

3. Stoney RJ, Cunningham CG. Acute mesenteric ischemia. Surgery. 1993;114(3):489-90.

4. Al-Diery H, Phillips A, Evennett N, Pandanaboyana S, Gilham $\mathrm{M}$, Windsor JA. The pathogenesis of nonocclusive mesenteric ischemia: implications for research and clinical practice. J Intensive Care Med. 2019;34(10):771-81.

5. Tilsed JV, Casamassima A, Kurihara H, Mariani D, Martinez I, Pereira J, Ponchietti L, Shamiyeh A, Al-Ayoubi F, Barco LA, Ceolin M, D'Almeida AJ, Hilario S, Olavarria AL, Ozmen MM, 
Pinheiro LF, Poeze M, Triantos G, Fuentes FT, Sierra SU, Soreide K, Yanar H. ESTES guidelines: acute mesenteric ischaemia. Eur J Trauma Emerg Surg. 2016;42(2):253-70.

6. Boley SJ, Sprayregan S, Siegelman SS, Veith FJ. Initial results from an agressive roentgenological and surgical approach to acute mesenteric ischemia. Surgery. 1977;82(6):848-55.

7. Aakhus T, Brabrand G. Angiography in acute superior mesenteric arterial insufficiency. Acta Radiol Diagn. 1967;6(1):1-12.

8. Athanasoulis CA, Wittenberg J, Bernstein R, Williams LF. Vasodilatory drugs in the management of nonocclusive bowel ischemia. Gastroenterology. 1975;68(1):146-50.

9. Trompeter M, Brazda T, Remy CT, Vestring T, Reimer P. Nonocclusive mesenteric ischemia: etiology, diagnosis, and interventional therapy. Eur Radiol. 2002;12(5):1179-87.

10. Woodhams R, Nishimaki H, Fujii K, Kakita S, Hayakawa K. Usefulness of multidetector-row CT (MDCT) for the diagnosis of non-occlusive mesenteric ischemia (NOMI): assessment of morphology and diameter of the superior mesenteric artery (SMA) on multi-planar reconstructed (MPR) images. Eur J Radiol. 2010;76(1):96-102.

11. Perez-Garcia C, de Miguel Campos E, Fernandez Gonzalo A, Malfaz C, Martin Pinacho JJ, Fernandez Alvarez C, Herranz Perez R. Non-occlusive mesenteric ischaemia: CT findings, clinical outcomes and assessment of the diameter of the superior mesenteric artery. Br J Radiol. 2018;91(1081):20170492.

12. Joosten A, Alexander B, Cannesson M. Defining goals of resuscitation in the critically ill patient. Crit Care Clin. 2015;31(1):113-32.

13. Wilms H, Mittal A, Haydock MD, van den Heever M, Devaud M, Windsor JA. A systematic review of goal directed fluid therapy: rating of evidence for goals and monitoring methods. J Crit Care. 2014;29(2):204-9.

14. Nieto FJ, Coresh J. Adjusting survival curves for confounders: a review and a new method. Am J Epidemiol. 1996;143(10):1059-68.

15. Sise MJ. Acute mesenteric ischemia. Surg Clin N Am. 2014;94(1):165-81.

16. Boley S. Persistent vasoconstriction-a major factor in nonocclusive mesenteric ischemia. Curr Top Surg Res. 1971;3:425-33.

17. Clark RA, Gallant TE. Acute mesenteric ischemia: angiographic spectrum. AJR Am J Roentgenol. 1984;142(3):555-62.

18. Stockmann H, Roblick UJ, Kluge N, Kunze U, Schimmelpenning H, Kujath P, Muller G, Bruch HP. Diagnosis and therapy of nonocclusive mesenteric ischemia (NOMI). Zentralbl Chir. 2000;125(2):144-51.

19. Klotz S, Vestring T, Rotker J, Schmidt C, Scheld HH, Schmid C. Diagnosis and treatment of nonocclusive mesenteric ischemia after open heart surgery. Ann Thorac Surg. 2001;72(5):1583-6.

20. Ernst S, Luther B, Zimmermann N, Bohner H, Wilke R, Feindt P, Furst G. Current diagnosis and therapy of non-occlusive mesenteric ischemia. RoFo : Fortschritte auf dem Gebiete der Rontgenstrahlen und der Nuklearmedizin. 2003;175(4):515-23.

21. Huwer H, Winning J, Straub U, Isringhaus H, Kalweit G. Clinically diagnosed nonocclusive mesenteric ischemia after cardiopulmonary bypass: retrospective study. Vascular. 2004;12(2):114-20.

22. Mitsuyoshi A, Obama K, Shinkura N, Ito T, Zaima M. Survival in nonocclusive mesenteric ischemia: early diagnosis by multidetector row computed tomography and early treatment with continuous intravenous high-dose prostaglandin E(1). Ann Surg. 2007;246(2):229-35.

23. Eris C, Yavuz S, Yalcinkaya S, Gucu A, Toktas F, Yumun G, Erdolu B, Ozyazicioglu A. Acute mesenteric ischemia after cardiac surgery: an analysis of 52 patients. Sci World J. 2013;2013:631534.

24. Bomberg H, Groesdonk HV, Raffel M, Minko P, Schmied W, Klingele M, Schafers HJ. Vasopressin as therapy during nonocclusive mesenteric ischemia. Ann Thorac Surg. 2016;102(3):813-9.

25. Stahl K, Busch M, Maschke SK, Schneider A, Manns MP, Fuge J, Wiesner O, Meyer BC, Hoeper MM, Hinrichs JB, David S. A retrospective analysis of nonocclusive mesenteric ischemia in medical and surgical ICU patients: clinical data on demography, clinical signs, and survival. J Intensive Care Med. 2019. https:// doi.org/10.1177/0885066619837911.

26. Niederhauser U, Genoni M, von Segesser LK, Bruhlmann W, Turina MI. Mesenteric ischemia after a cardiac operation: conservative treatment with local vasodilation. Ann Thoracic Surg. 1996;61(6):1817-9.

27. Ambe PC, Kang K, Papadakis M, Zirngibl H. Can the preoperative serum lactate level predict the extent of bowel ischemia in patients presenting to the emergency department with acute mesenteric ischemia? BioMed Res Int. 2017;2017:8038796.

28. Simundic AM. Measures of diagnostic accuracy: basic definitions. Ejifcc. 2009;19(4):203-11.

29. Eker A, Malzac B, Teboul J, Jourdan J. Mesenteric ischemia after coronary artery bypass grafting: should local continuous intraarterial perfusion with papaverine be regarded as a treatment? Eur J Cardio-Thorac Surg. 1999;15(2):218-20.

30. Mahlke C, Kuhn JP, Mensel B, Schreiber A, Juretzko A, Steinbach A, Grisk O. Iloprost, prostaglandin e1, and papaverine relax human mesenteric arteries with similar potency. Shock (Augusta, Ga.). 2017;48(3):333-9.

Publisher's Note Springer Nature remains neutral with regard to jurisdictional claims in published maps and institutional affiliations. 